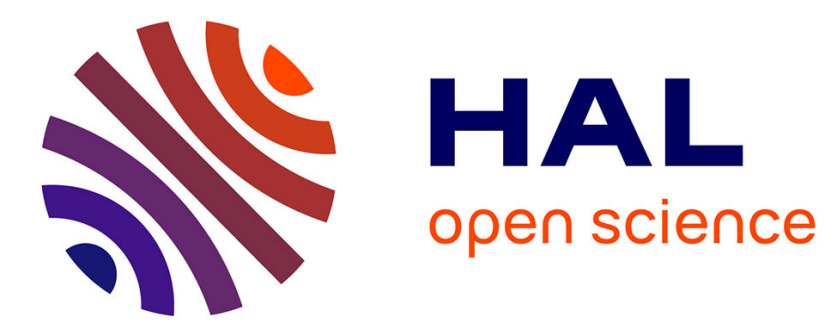

\title{
Design of statistics learning environments
}

Dani Ben-Zvi, Koeno Gravemeijer, Janet Ainley

\section{To cite this version:}

Dani Ben-Zvi, Koeno Gravemeijer, Janet Ainley. Design of statistics learning environments. Eleventh Congress of the European Society for Research in Mathematics Education (CERME11), Utrecht University, Feb 2019, Utrecht, Netherlands. hal-02410840

\section{HAL Id: hal-02410840 https://hal.science/hal-02410840}

Submitted on 14 Dec 2019

HAL is a multi-disciplinary open access archive for the deposit and dissemination of scientific research documents, whether they are published or not. The documents may come from teaching and research institutions in France or abroad, or from public or private research centers.
L'archive ouverte pluridisciplinaire HAL, est destinée au dépôt et à la diffusion de documents scientifiques de niveau recherche, publiés ou non, émanant des établissements d'enseignement et de recherche français ou étrangers, des laboratoires publics ou privés. 


\title{
Design of statistics learning environments ${ }^{1}$
}

\author{
$\underline{\text { Dani Ben-Zvi }}{ }^{1}$, Koeno Gravemeijer ${ }^{2}$ and Janet Ainley ${ }^{3}$ \\ ${ }^{1}$ University of Haifa, Israel; dbenzvi@univ.haifa.ac.il \\ ${ }^{2}$ Eindhoven University of Technology, Eindhoven, Netherlands; Koeno@ gravemeijer.nl \\ ${ }^{3}$ University of Leicester, UK; jma30@1e.ac.uk
}

The goal of this article is to draw attention to the need to think about learning environments and their design as a way of considering how sustainable change in the learning and teaching of statistics can be supported. The goal is not to advocate one particular approach to the design of learning environments, but rather to raise awareness of the need to consider this lens in statistics education. We first present the rationale for the importance of a focus on learning environments for statistics education. We consider six design considerations for statistics learning environments. Finally, we discuss implications and emerging directions and goals for further implementation and research.

Keywords: Learning environment, learning and teaching of statistics, statistics education.

\section{Introduction}

Many of the research studies in the learning and teaching of statistics (e.g., Ben-Zvi, Makar, \& Garfield, 2018) suggest innovative approaches that differ from the traditional classroom practices through which most current statistics teachers learned this subject themselves. However, innovation which addresses only one aspect of the pedagogical context, for example introducing technological tools in teaching when assessment practices remain unchanged, is likely to have only limited impact. This article offers starting points of design for deep learning of statistics to develop students' statistical reasoning. To do this, we use a learning environment perspective to provide a dynamic, holistic, integrated and multi-dimensional framework for sustainable educational change in statistics. The goal of this article is to draw attention to the need to think about learning environments and their design as a way of considering how sustainable change in the learning and teaching of statistics can be supported.

A learning environment is a complex and dynamic educational system, composed of multiple factors: key statistical ideas and competencies (content), engaging tasks, real or realistic data sets, technological tools, classroom culture including modes of discourse and argumentation amongst students and between students and teachers, norms and emotional aspects of engagement and assessment methods. Integrating all these factors in order to reform the way statistics is learnt and taught is a challenging endeavor. The focus in this article is on general characteristics of statistics learning environments that need to be examined and integrated in light of the new developments in mathematics, statistics and science education, and more generally in the learning sciences. Our specific objectives are to first present the rationale for the importance of a focus on learning environments for statistics education; we provide a potential framework for considering aspects of

\footnotetext{
${ }^{1}$ This article is based on a chapter by Ben-Zvi, Gravemeijer and Ainley (2018).
} 
statistics learning environments. We then develop six design considerations for statistics learning environments. Finally we discuss implications and emerging directions and goals for further implementation and research.

\section{Learning environments}

The research literature in statistics education is filled with success stories, which are of importance to the advancement of the field, but have not had a major impact on the way statistics is taught in all levels of education. We propose that one of the reasons for this is the lack of a systematic, comprehensive and integrated approach to design for educational change (e.g., Cuban, 2003). We suggest that what is needed is change in a combination of interrelated dimensions (content, pedagogy, space, time, tasks, tools, assessment, classroom culture etc.) that can bring about significant and sustainable reform in the teaching and learning of statistics by providing a coherent framework in which each dimension operates synergistically with others. Moore (1997) similarly urged a reform of statistics instruction and curriculum based on strong synergies between content, pedagogy and technology. A learning environment perspective can provide such a framework. One of the major goals of statistics education is to educate critical, independent and statistically-literate learners who are able to study topics of their own interest and become involved in data-based decisions. A learning environment perspective can provide fertile affordances to support learners' growth and development in this direction as well as a guiding framework for teachers that can support their professional growth in statistics education.

Design dimensions of statistics learning environments that will be considered and discussed in this article are based on a number of principles arising from recent research. In particular we have drawn on research concerning the importance of prior knowledge and preference for depth over breadth (Bransford et al., 2000), the creation of failure-safe learning communities in which students can learn from their successes and mistakes (Kapur \& Bielaczyc, 2012), the nurture and articulation of learners' diverse expertise, encouragement of reflection and feedback (Boud, Keogh, \& Walker, 1985), formative assessment (Kingston \& Nash, 2011) and enculturation into the statistics discipline (Edelson \& Reiser, 2006).

The use of the metaphor of an environment emphasizes that classrooms are interacting social, cultural, physical, psychological and pedagogical systems rather than a collection of resources, tasks and activities or a list of separate factors that influence learning. Because of the complex nature of learning environments, successful design requires a working model of how components of the design that help frame forms of student participation and responsibility, are collectively constituted and orchestrated (Lehrer, 2009). To achieve this kind of balance and orchestration we argue that learning environments must be designed on the basis of learning theories, which can guide the design, help choose between the options and lead to better achievement of the pedagogical goals. In Ben-Zvi, Gravemeijer and Ainley (2018), we describe two theoretical frameworks that have been commonly used to guide the construction of learning environments: social constructivist theory as a background theory on teaching and learning and Realistic Mathematics Education (RME) as domain-specific instruction theory that is specific for mathematics education. 


\section{Design dimensions for statistics learning environment}

In this section, we identify design dimensions that arise from theoretical and empirical sources. These dimensions are not meant to serve as a prescription for what teachers and designers should do, but rather to provide a wide spectrum of factors or starting points, that need to be considered, aligned and balanced in designing statistics learning environments. The goal of designing effective and positive statistics learning environments occurs in a wide continuum of settings. On this continuum, this article focuses on designed learning environments rather than informal and ambient ways of learning. The goal of these learning environments is for students to develop a deep and meaningful understanding of statistics and the ability to think and reason statistically. We discuss and expand on six dimensions of pedagogical design (Figure 1) proposed by Cobb and McClain (2004), highlighting what we see as the important connections between them.

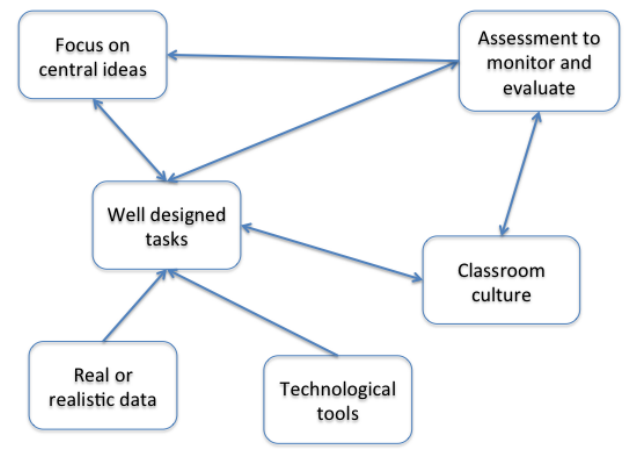

Figure 1: A web of interrelated dimensions of a learning environment

\section{Focus on Developing Central Statistical Ideas Rather Than on Tools and Procedures}

There are several key statistical ideas that students are expected to understand at a deep conceptual level (Garfield \& Ben-Zvi, 2008). These ideas serve as overarching goals that direct teaching and motivate and guide students' learning. They include data, distribution, center, variability, comparing groups, sampling, modeling, inference and covariation. Garfield and Ben-Zvi (2008), in their Statistical Reasoning Learning Environment (SRLE), advocate a focus on key statistical ideas and the interrelations among them and suggest ways to present these ideas throughout a course, revisiting them in different contexts, illustrating their multiple representations and interrelationships, and helping students recognize how they form the supporting structure of statistical knowledge.

\section{Use Well-Designed Tasks to Support the Development of Statistical Reasoning}

An important part of a statistics learning environment is the use of carefully designed tasks, informed by research findings, that promote student learning through collaboration, interaction, discussion and addressing interesting problems (Roseth, Garfield, \& Ben-Zvi, 2008). It may be argued that such tasks should be part of a well-considered instructional sequence, informed by the aim of developing central statistical ideas, which is underpinned by a local instruction theory. A local instruction theory typically consists of a theory about a potential learning process and theories about the means of supporting that learning process (Gravemeijer \& Cobb, 2013). The former offers 
teachers background information, on the basis of which they may decide, on a daily basis, what learning goals to aim for. While the latter offer them information on how potential tasks, tools, ways of interacting and the classroom culture may support the intended learning process. This information will help teachers in choosing tasks and tools, anticipating the mental activities of the students, orchestrating classroom interaction and evaluating the implied hypothetical learning trajectories.

\section{Use Real or Realistic and Motivating Data Sets}

The design of pedagogic tasks in statistics must take account of the data that will be centrally involved. Data are at the heart of statistical work and data should be the focus for statistical learning as well (Franklin \& Garfield, 2006). Throughout their experience of learning statistics, students need to consider methods of data collection and production and how these methods affect the quality of the data and the types of analyses that are appropriate. One approach can be to look for interesting data sets to motivate students to engage in activities, especially ones that ask them to make conjectures about a data set before analyzing it (Ben-Zvi \& Aridor, 2016). Another approach would be to start with a question and then discuss what data would be needed to answer it. However the provision of real or 'realistic' data is not always sufficient to engage students in tasks that develop statistical reasoning unless the task poses meaningful challenges and provides opportunities to use statistical ideas in realistic ways.

Consider two kinds of activities using real data which are relatively familiar within statistics education research. The first is exploratory data analysis based on a source of real data. Although data about students like themselves may have intrinsic interest, posing meaningful questions about the data can be challenging for school students (Burgess, 2007). Open-ended exploration of relationships in the data without a clear goal may not lead them to use statistical ideas in realistic ways. The second is a sampling task, such as repeatedly drawing small samples to estimate the proportion of sweets of a particular color within a bowl. Here the statistical idea of sampling is being used in a realistic way, to answer a specific question, but the task itself is not a meaningful challenge (Ainley, Gould, \& Pratt, 2015). If you really wanted to know the numbers of sweets of different colors it would be quicker and more reliable to empty the bowl and count them. What these tasks have in common is that, although based on real data, they do not emphasize opportunities for students to appreciate the utility of statistical ideas. As a result they may appear contrived and fail to engage and motivate students.

There is a further tension concerning the role and nature of data in statistics tasks. Students, particularly younger students, need to experience collecting, recording and cleaning their own data in order to develop their understandings of different forms of representation (Neumann, Hood, \& Neumann, 2013). But data collection is time-consuming, often leaving relatively little time for analysis and discussion and the features of the resulting data sets cannot be predicted. Providing real world data sets, or devising data sets which are not authentic but embody the features that the teacher wants students to experience, will save time but students may find such data sets harder to understand and engage with (Arnold, 2004). 


\section{Integrate the Use of Technological Tools That Allow Students to Explore and Analyze Data}

The design of tasks and the ways in which students may access and explore data are significantly influenced by the range of technological tools available to support the development of students' understanding and reasoning, such as computers, graphing calculators, statistical software and web applets (Biehler, 2003). Students no longer have to spend time performing tedious calculations, or drawing graphs and can focus instead on the more important task of learning how to choose appropriate analytic methods and how to interpret results. Technological tools are used not only to generate statistics, graph or analyze data, but also to help students visualize concepts and develop an understanding of abstract ideas through simulations. For examples of innovative tools and ways to use them to help develop students' reasoning, see Biehler, Ben-Zvi, Bakker and Makar (2013).

\section{Establish a Classroom Culture that Fosters Statistical Arguments}

The design of tasks, technological and assessment tools has to take into account the expected forms of classroom discourse. In statistics learning environments, the use of activities and technology allows for a form of classroom discourse in which student learn to question each other and respond to such questions, as well as explaining their answers and arguments. Cobb and McClain (2004) describe the effective classroom discourse in which statistical arguments explain why the organization of data gives rise to insights about the phenomenon under investigation and students engage in sustained exchanges that focus on significant statistical ideas.

It can be challenging to create a statistics learning environment with classroom discourse that enables students to engage in discussions in which significant statistical issues emerge and where arguments are presented and their meaning is openly negotiated. Creating a classroom climate where students feel safe expressing their views, even if they are tentative is another challenging task and is related to classroom culture, in which the teacher and students have to develop the corresponding classroom social norms and socio-mathematical (or socio-statistical) norms (Yackel $\&$ Cobb, 1996). These norms encompass the obligation for the students to explain and justify their solutions, to try to understand the explanations and reasoning of the other students, to ask for clarification when needed and eventually to challenge the ways of thinking with which they do not agree. The teacher is not expected to give explanations, but to pose tasks and ask questions that may foster students' thinking. Socio-statistical norms would be tailored to what it means to do statistics, for example what a statistical problem is, what a statistical argument is and so forth.

The shift in the classroom culture is related to a potential shift in the role of the students, from problem solvers to statisticians who analyze and represent data to make them easily accessible for decision makers. When adopting the role of a data analyst, or data detective (Pfannkuch \& Rubick, 2002), students can start reflecting on the adequacy and clarity of condensed descriptions and representations of data, which may foster the reinvention of more sophisticated representations and concepts. 


\section{Use Assessment to Monitor the Development of Students' Statistical Learning and to Evaluate Instructional Plans}

Assessment should be aligned to well-designed tasks that focus on central statistical ideas in a discourse-rich classroom. Much of the value of changes in the other design dimensions will be lost if assessment practices are not aligned in this way, since the attention of students and teachers will be shaped by the requirements of assessment. In recent years, many alternative forms of assessment have been used in statistics classes. In addition to quizzes, homework and exams, many teachers use statistical projects as a form of assessment (MacGillivray \& Pereira-Mendoza, 2011). Other forms of alternative assessment are also used to assess students' statistical literacy (e.g., critique a graph in a newspaper) and reasoning (e.g., write a meaningful short essay), or to provide feedback to the teacher (e.g., minute papers).

Assessments need to be aligned with learning goals, focusing on understanding key ideas and not just on skills, procedures and computed answers. This can be done with formative assessments used during a course (e.g., quizzes, small projects, or observing and listening to students in class) as well as with summative evaluations (course grades). Useful and timely feedback is essential for assessments to lead to learning. Types of assessment may be more or less practical in different types of courses. However, it is possible, even in large classes, to implement good assessment practices (Garfield \& Ben-Zvi, 2008, pp. 65-89).

\section{Discussion: Contemporary issues and emerging directions}

The goal of this article has been to draw attention to the need to think about learning environments and their design in statistics education as a way of considering how sustainable change in the learning and teaching of statistics can be supported. We have provided six dimensions of statistics learning environments. Designing for educational change to support the development of students' statistical reasoning is a challenging task. Using a lever to make a one-dimensional change (e.g., formulate new tasks, use of a new pedagogical strategy) may make a difference that is not necessarily a sustainable change in students' understanding of statistical ideas. This article has argued for a holistic and integrated approach that advocates a learning environment where students are engaged in making and testing conjectures using data, discussing and explaining statistical reasoning, focusing on the important big ideas of statistics, using innovative tools in creative ways to assist their learning and being assessed in appropriate ways.

A key factor in this discussion is that these six dimensions, which are inter-related (see Figure 1), must be aligned and balanced. Issues of alignment are important for accelerating statistics learning both within and outside of schools. The meaning of these design principles being part of integrative whole is that using one of them separately is not enough to make deep and sustainable change in students' learning. The learning environment approach helps to interlink them. For example, the design of motivating tasks is linked to real data collection; these data can be used to build students' statistical understanding taking advantages of the innovative affordances of technological tools; productive classroom discourse is supported by the design of open-ended tasks that support argumentation and by appropriate responses by the teacher; assessment methods need to align with 
the design of tasks; a provision of a new tool must consider the potential interactions with content and pedagogy (Moore, 1997).

Thus we argue that pedagogical and research efforts for change must consider the interactions among these dimensions. There are however other important dimensions of learning environments that were not included in this article. One example is the emotional aspects of engagement and identity to motivate all students to participate and reflect on their experiences (Heyd-Metzuyanim, 2013). In addition, the broader community (school level policy makers, local and national authorities, etc.) plays a significant role in the constitution of the learning environment. For example, tensions may arise between required traditional examinations and alternative assessment methods employed in a learning environment or between national curricula and an emergent and dynamic learning trajectory in the learning environment.

Further research is crucially needed to provide more well-researched holistic examples in different contexts and age levels. Systematic studies are also needed about the effectiveness of statistics learning environments, learning environment design issues, the role of alignment between the various dimensions of statistics learning environments, new possibilities for teaching and learning in innovative designs; and opportunities in cutting edge areas, such as, model-based reasoning, visual representation to teach complex abstract concepts, learning in virtual worlds, net-based collaborative teams and communities and big data.

The difficulty of demonstrating the effectiveness of learning environments, raises profound methodological issues in researching them. The learning environment approach acknowledges a complex system or ecology in which a traditional methodology is not sustainable. Instead, a design research approach (Cobb et al., 2003) is needed, where iterative design of the learning environment sensitizes the research team to the key mechanisms for learning within the design. We recommend that more attention be given to methodological aspects of researching the design of learning environments.

First steps in moving towards the learning environment perspective in the statistics education community are for researchers to consider the implications of this approach in their studies and for professional development to support teachers to consider how current curricula and materials align in the context of social, cultural, physical, psychological and pedagogical components of a learning environment. Careful and steady change over a period of time, rather than a push for radical change, may lead to a successful implementation of a learning environment in the statistics education world, both among researchers and teachers.

\section{References}

Ainley, J., Gould, R., \& Pratt D. (2015). Learning to reason from samples: commentary from the perspectives of task design and the emergence of "big data." Educational Studies in Mathematics, 88(3), 405-412.

Arnold, P. (2014). Statistical investigative questions: An enquiry into posing and answering investigative questions from existing data. Unpublished doctoral thesis, University of Auckland, New Zealand.

Ben-Zvi, D., \& Aridor, K. (2016). Children's wonder how to wander between data and context. In D. Ben-Zvi and K. Makar. (Eds.), The teaching and learning of statistics: International 
perspectives (pp. 25-36). Springer International Publishing Switzerland.

Ben-Zvi, D., Gravemeijer, K., \& Ainley, J. (2018). Design of statistics learning environments. In D. Ben-Zvi, K. Makar, \& J. Garfield (Eds.), International handbook of research in statistics education (pp. 473-502). Springer Cham.

Ben-Zvi, D., Makar, K., \& Garfield, J. (Eds.) (2018). International handbook of research in statistics education. Springer Cham.

Biehler, R. (2003). Interrelated learning and working environments for supporting the use of computer tools in introductory classes. In International Statistical Institute (Ed.): CD-ROM Proceedings of the IASE satellite conference on Statistics Education and the Internet, MaxPlanck-Institute for Human Development, Berlin, 11-12 August 2003, Voorburg: Netherlands.

Biehler, R., Ben-Zvi, D., Bakker, A., \& Makar, K. (2013). Technology for enhancing statistical reasoning at the school level. In M. A. Clements, A. Bishop, C. Keitel, J. Kilpatrick, and F. Leung (Eds.), Third International Handbook of Mathematics Education (pp. 643-690). Springer.

Boud, D., Keogh, R., \& Walker, D. (1985). Promoting reflection in learning: A model. In D. Boud, R. Keogh and D. Walker (Eds.), Reflection: Turning experience into learning (pp. 18-39). East Brunswick, NJ: Nichols.

Bransford, J., Brown, A. L., \& Cocking, R. R. (Eds.) (2000). How people learn: Brain, mind, experience, and school. Washington, DC: National Academy Press.

Burgess, T. (2007). Investigating the nature of teacher knowledge needed and used in teaching statistics. Unpublished doctoral thesis, Massey University, New Zealand.

Cobb, P., \& McClain, K. (2004). Principles of instructional design for supporting the development of students' statistical reasoning. In D. Ben-Zvi \& J. Garfield (Eds.), The challenge of developing statistical literacy, reasoning, and thinking (pp. 375-396). Dordrecht, Netherlands: Kluwer Academic Publishers.

Cobb, P., Confrey, J., diSessa, A., Lehrer, R., \& Schauble, L. (2003). Design Experiments in Educational Research. Educational Researcher, 32(1), 9-13.

Cuban, L. (2003). Why is it so hard to get good schools? New York: Teachers College, Columbia University.

Edelson, D., \& Reiser, B. (2006). Making authentic practices accessible to learning: Design challenges and strategies. In R. K. Sawyer (Ed.), The Cambridge Handbook of the Learning Sciences (pp. 335-354). New York, NY: Cambridge University Press.

Franklin, C., \& Garfield, J. (2006). The Guidelines for Assessment and Instruction in Statistics Education (GAISE) project: Developing statistics education guidelines for pre K-12 and college courses. In G.F. Burrill, (Ed.), Thinking and reasoning about data and chance: Sixty-eighth NCTM Yearbook (pp. 345-375). Reston, VA: National Council of Teachers of Mathematics.

Garfield, J., \& Ben-Zvi, D. (2008). Developing students' statistical reasoning: Connecting research and teaching practice. Dordrecht, the Netherlands: Springer.

Heyd-Metzuyanim, E. (2013). The co-construction of learning difficulties in mathematicsteacher-student interactions and their role in the development of a disabled mathematical identity. Educational Studies in Mathematics, 83(3), 341-368.

Kapur, M., \& Bielaczyc, K. (2012). Designing for productive failure. Journal of the Learning Sciences, 21(1), 45-83.

Kingston, N., \& Nash, B. (2011). Formative assessment: A meta-analysis and a call for research. Educational Measurement: Issues and Practice, 30(4), 28-37.

Lehrer, R. (2009). Designing to develop disciplinary knowledge: Modeling natural systems. American Psychologist, 64(8), 759-771.

MacGillivray, H., \& Pereira-Mendoza, L. (2011). Teaching statistical thinking through investigative projects. In C. Batanero, G. Burrill \& C. Reading (eds.), Teaching statistics in school mathematics-challenges for teaching and teacher education (pp. 109-120). Springer. 
Moore, D. S. (1997). New pedagogy and new content: The case of statistics. International Statistical Review, 65(2), 123-137.

Neumann, D. L., Hood, M., \& Neumann M. M. (2013). Using real-life data when teaching statistics: Student perceptions of this strategy in an introductory statistics course. Statistics Education Research Journal, 12(2), 59-70.

Pfannkuch, M., \& Rubick, A. (2002). An exploration of students' statistical thinking with given data. Statistics Education Research Journal, 1(2), 4-21.

Roseth, C. J., Garfield, J. B., \& Ben-Zvi, D. (2008). Collaboration in learning and teaching statistics. Journal of Statistics Education, 16(1), 1-15.

Yackel, E., \& Cobb, P. (1996). Sociomathematical norms, argumentation, and autonomy in mathematics. Journal for Research in Mathematics Education, 27(4), 458-477. 